\title{
Asian house rats may facilitate their invasive success through suppressing brown rats in chronic interaction
}

\author{
Hong-Ling Guo ${ }^{1,2}$, Hua-Jing Teng ${ }^{1,2}$, Jin-Hua Zhang ${ }^{1}$, Jian-Xu Zhang ${ }^{1 *}$ and Yao-Hua Zhang ${ }^{1 *}$ (D)
}

\begin{abstract}
Background: The Asian house rat (Rattus tanezumi) and the brown rat (Rattus norvegicus) are closely related species and are partially sympatric in southern China. Over the past 20 years, $R$. tanezumi has significantly expanded northward in China and partially replaced the native brown rat subspecies, $R$. n. humiliatus. Although invasive species are often more aggressive than native species, we did not observe interspecific physical aggression between $R$. tanezumi and $R$. n. humiliatus. Here, we focused on whether or not $R$. tanezumi was superior to $R$. n. humiliatus in terms of nonphysical competition, which is primarily mediated by chemical signals.

Results: We performed two laboratory experiments to test different paradigms in domesticated R. tanezumi and R. $n$. humiliatus. In Experiment 1, we caged adult male rats of each species for 2 months in heterospecific or conspecific pairs, partitioned by perforated galvanized iron sheets, allowing exchange of chemical stimuli and ultrasonic vocalization. The sexual attractiveness of male urine odor showed a tendency (marginal significance) to increase in $R$. tanezumi caged with R. n. humiliatus, compared with those in conspecific pairs. Hippocampal glucocorticoid receptor (GR) and brainderived nutrition factor (BDNF) mRNA were upregulated in $R$. n. humiliatus and $R$. tanezumi, respectively, when the rats were caged in heterospecific pairs. In Experiment 2, we kept juvenile male rats in individual cages in rooms with either the same or the different species for 2 months, allowing chemical interaction. The sexual attractiveness of male urine was significantly enhanced in $R$. tanezumi, but reduced in $R$. n. humiliatus by heterospecific cues and mRNA expression of hippocampal GR and BDNF were upregulated by heterospecific cues in $R$. n. humiliatus and $R$. tanezumi, respectively. Although not identical, the results from Experiments 1 and 2 were generally consistent.

Conclusions: The results of both experiments indicate that nonphysical/chronic interspecific stimuli, particularly scent signals, between $R$. n. humiliatus and R. tanezumi may negatively affect $R$. n. humiliatus and positively affect $R$. tanezumi. We infer that chronic interspecific interactions may have contributed to the invasion of $R$. tanezumi into the range of $R$. n. humiliatus in natural habitats.
\end{abstract}

Keywords: Closely related species, Invasive mechanism, Sexual attractiveness, Neuroendocrine molecules, Chronic stress

\section{Background}

The brown rat (Rattus norvegicus), the Asian house rat ( $R$. tanezumi), and the black rat $(R$. rattus) are three closely related commensal pests [1]. $R$. norvegicus has now spread from northern Asia to all continents except Antarctica, whereas $R$. tanezumi is mainly distributed in

\footnotetext{
* Correspondence: zhangjx@ioz.ac.cn; zhangyh@ioz.ac.cn

${ }^{1}$ State Key Laboratory of Integrated Management of Pest Insects and Rodents in Agriculture, Institute of Zoology, Chinese Academy of Sciences, No.1-5 Beichen West Road, Chaoyang District, Beijing 100101, China

Full list of author information is available at the end of the article
}

eastern, southern, and south-eastern Asia [1-3]. In China, $R$. norvegicus is widespread and has differentiated into four subspecies, including $R$. n. norvegicus, $R . n$. soccer, $R$. n. humiliatus, and $R$. n. caraco, whereas $R$. tanezumi typically lives south of the Yellow River and is sympatric with $R$. n. norvegicus and $R$. n. soccer $[1,4,5]$. $R$. tanezumi is also sympatric with $R$. n. caraco in the Korean peninsula [6]. $R$. n. humiliatus, which is the smallest of the four subspecies and lives mainly in Hebei Province in central North China, is the only subspecies geographically isolated from $R$. tanezumi $[4,7]$; however, 
$R$. tanezumi has recently expanded its range to north of the Yellow River in the south of Hebei Province and partially replaced the native $R$. norvegicus subspecies (i.e., $R$. $n$. humiliatus) [8-10]. Several factors, including global warming and higher resistance to common rodenticides compared with brown rats, are believed to likely contribute to the invasive success of $R$. tanezumi $[5,11-15]$.

Exotic invasive species that successfully expand their range and displace native species appear to exhibit superiority in interspecific competition [16]. As closely related species are more likely to compete than those that are more distantly related, their competition, coexistence, and invasion have been extensively studied [16-20]. There are several types of interspecific competition, including indirect resource competition, interspecific aggression, interspecific territoriality, overgrowth, and chemical competition $[16,21]$. In the case of rodents, invasive species are often more aggressive than native species [22]. While spreading from Asia to Europe and America during the Middle Ages, $R$. norvegicus generally displaced $R$. rattus in human settlements, where they out-competed $R$. rattus via physical interspecific interactions [11, 23]. It is logical that $R$. norvegicus is superior to $R$. rattus in terms of interspecific aggression, since the former is larger than the latter [1]; however, invasive $R$. tanezumi is generally smaller than native $R$. n. humiliatus. We did not observe that male $R$. $n$. humiliatus and $R$. tanezumi displayed interspecific aggression in dyadic encounters in a neutral arena (a common laboratory method to investigate aggressive behavior), and they can even live peacefully together for long periods of time when caged in interspecific malemale pairs $[1,19]$ (unpublished data). Thus, it is necessary to explore whether other types of interspecific competition (e.g., nonphysical interaction) contribute to the successful invasion of $R$. tanezumi into areas containing $R . n$. humiliatus.

Interspecific chemical interactions, including communication signaling and allelopathy, are widespread among prokaryotes, plants, and invertebrates, and are important in the invasion of exotic species [12, 14, 24]. For mammals, odor-mediated communication between different species (e.g., during predator and prey interactions) is also important, and the general laws of chemical ecology apply $[25,26]$. Rodents use scent signals extensively in species recognition and interspecific competition [25, 27-30]. In rodents, scent signals, including urine volatile compounds and major urine proteins, are distinctive between closely related species and even between subspecies, including $R$. n. humiliatus and $R$. tanezumi [31-38] (unpublished data). The scent signals released by animals can function in heterospecific, as well as conspecific interactions, without the physical presence of the donor [37, 39-41]. Therefore, in rodents, where physical antagonism does not exist, interspecific competition may rely partially or completely on interspecific odor-based effects.

Interspecific competition can induce physiological stress responses and inhibitory effects on some phenotypic traits of competitors [20, 42]. In rodents, male scent signals have crucial roles in mediating sexual behavior and are often correlated with reproductive success [43-46]. If interspecific interactions induce strong chronic social stress, they can impair the attractiveness of the odor of male urine to females, and the production of urinary sex pheromones, and consequently disturb rodent reproductive behavior [47-50]. Conversely, changes in the sexual attractiveness of males subjected to interspecific competition may indicate stressful states in their competitors.

Competition-induced stress can activate the hypothalamic-pituitary-adrenal (HPA) axis to release endocrine hormones and neurotransmitters and alter gene expression in some regions of the rodent brain $[25,51-54]$. After chronic competition, shifts in glucocorticoid levels are not always detectable in rodents [20]. The hippocampus is exquisitely sensitive to stressors, due to direct emotional input from the basolateral amygdala (BLA) and glucocorticoids (GCs), and because of its high density of GC receptors $[55,56]$. The mRNA expression of hippocampal glucocorticoid receptor $(G R)$, brain-derived neurotrophic factor $(B D N F)$, and the BDNF receptor $(\operatorname{Trk} B)$ can be affected by stressors through modulation of the HPA axis and emotionrelated input from the BLA [52-54]. Levels of GR, $B D N F$, and TrkB are closely related to emotional behavior, neuronal development, and plasticity, and can thus reflect emotional states in rodents [55, 57-59]. Stressors often impart different effects on adult and juvenile animals [60]. Early exposure to aversive stimuli often causes long-term alterations in many aspects of behavior, such as behavioral regulation, neuroendocrine responsiveness to stress, and mRNA expression of central nervous system genes related to behavioral change in rodents [61].

In the current study, we aimed to explore the potential roles of chronic nonphysical/chemical competition in the natural invasion process of $R$. tanezumi replacing $R$. n. humiliatus using laboratory experiments. Therefore, we performed two long-term experiments to test different paradigms in our laboratory. In Experiment 1, two adult male rats of the same or different species were caged together, partitioned by a perforated galvanized iron sheet; in Experiment 2, juvenile males of these two rat species were exposed to heterospecific or conspecific odors. To examine the effects of these exposures, we then evaluated changes in the sexual attractiveness of male urine 
odor and determined the mRNA levels of hippocampal GR, BDNF, and $\operatorname{TrkB}$, as well as serum cortisol concentrations.

\section{Results}

Effects of chronic interspecific interaction on body weight Experiment 1: After two months of interaction, the body weight was not significantly different between the control and treatment groups of either $R$. $n$. humiliatus or R. tanezumi (Fig. 1a).

Experiment 2: After two months of interaction, the body weight of immature males exposed to a heterospecific odor was higher than that of the control group $(t=$ 2.232, $n=6$ for each group, $p=0.050$ ) in $R$. $n$. humiliatus, whereas body weight did not differ between the control and treatment groups in $R$. tanezumi (Fig. 1b).

\section{Sexual attractiveness of male urine odor}

Experiment 1: In $R . n$. humiliatus, female attraction to male urine did not differ between the control and treatment groups (Fig. 2a), while in $R$. tanezumi, females exhibited a trend towards preferring males caged with $R . n$. humiliatus over those caged with their own species $(z=$ 1.726, $n=12, p=0.080$, marginal significance) (Fig. 2a).

Experiment 2: In $R$. n. humiliatus, heterospecific odor stimulation significantly suppressed the sexual attractiveness of male urine to conspecific females compared with conspecific odor stimulation $(z=2.884, n=16, p=0.004$ ) (Fig. 2b). Conversely, the sexual attractiveness of male urine was significantly greater after heterospecific odor stimulation in $R$. tanezumi $(z=2.373, n=18, p=0.018)$ (Fig. 2b).

\section{Serum cortisol and testosterone levels}

Experiment 1: A radioimmunoassay demonstrated that serum testosterone and cortisol levels were not significantly different between the control and treatment groups for either $R$. n. humiliatus or $R$. tanezumi (3a and b). However, serum cortisol concentration was higher in both the control and treatment groups of $R$. tanezumi than those of $R$. n. humiliatus (control group: $t=2.938, n=12$ for each species, $p=0.008$; treatment group: $t=3.395, n=9-10$ for each species, $p=0.004$ ) (Fig. 3a).

Experiment 2: Similarly, interspecific odor stimulation had no apparent effect on serum testosterone or cortisol levels within species for either $R$. n. humiliatus or $R$. tanezumi (Fig. 3c and d). R. tanezumi also had a higher serum cortisol concentration than $R$. n. humiliatus in both the control $(t=3.173, n=6-7$ for each species, $p=$ $0.009)$ and treatment $(t=3.445, n=6-8$ for each species, $p=0.005)$ groups (Fig. 3c).

\section{Gene expression of $G R$ and $B D N F$ in the hippocampus}

Experiment 1: Quantitative real-time PCR demonstrated that GR mRNA expression was slightly upregulated in the hippocampus of $R$. n. humiliatus rats exposed to heterospecific stimuli $(t=1.901, n=8$ for each group, $p=$ 0.078, marginal significance), whereas hippocampal $B D N F$ was significantly upregulated in $R$. tanezumi exposed to heterospecific stimuli $(z=3.361, n=8$ for each group, $p=0.001$ ) (Fig. 4a and b). Hippocampal TrkB mRNA expression exhibited no significant changes within either rat species (Fig. 4a and b).

Experiment 2: Similar to the results of Experiment 1, hippocampal GR mRNA expression $(t=4.125, n=6$ for each group, $p=0.009$ ) in $R$. $n$. humiliatus and $B D N F$ mRNA expression $(t=1.911, n=7-8$ for each group, $p=0.078$, marginal significance) in $R$. tanezumi were upregulated (Fig. 4c and d). Hippocampal TrkB mRNA expression showed no change within either rat species.

\section{Discussion}

Our results from binary choice tests suggest that chronic nonphysical competition between $R$. tanezumi and $R . n$.
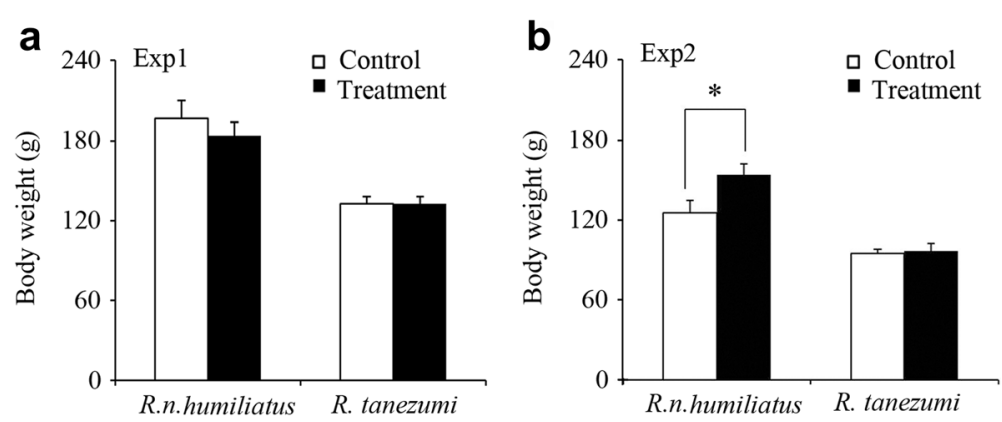

Fig. 1 Comparison of final body weights (mean $\pm \mathrm{SE}, \mathrm{g}$ ) between control and treatment groups of $R$. norvegicus humiliatus or $R$. tanezumi in Experiment 1 (Exp1) (a) $\left(n_{\text {control }}=n_{\text {treatment }}=9\right.$ for $R$. $n$. humiliatus and $n_{\text {control }}=9, n_{\text {treatment }}=10$ for $R$. tanezumi.) and Experiment 2 (Exp2) $(\mathbf{b})\left(n_{\text {control }}=n_{\text {treatment }}=6\right.$ for $R$. $n$. humiliatus; $n_{\text {control }}=7$ and $n_{\text {treatment }}=8$ for $R$. tanezumi $)$. Independent samples $t$-test or MannWhitney $U$-test; ${ }^{*} p \leq 0.05$ 

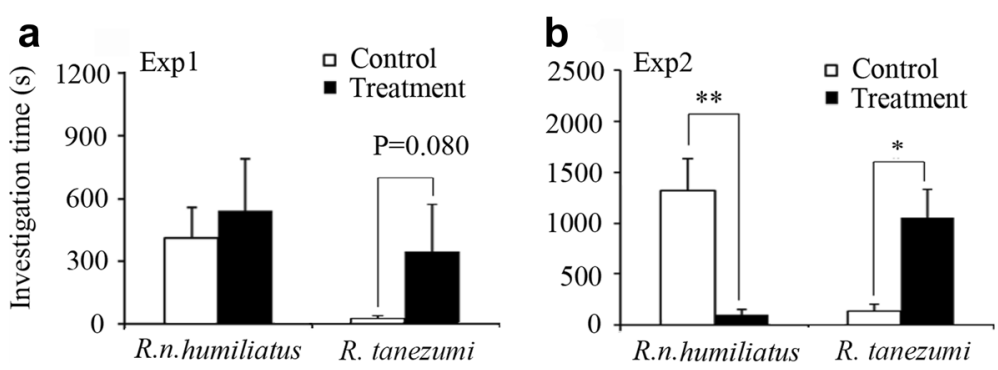

Fig. 2 Investigation time (mean $\pm \mathrm{SE}$, sec) spent by female $R$. norvegicus humiliatus or $R$. tanezumi on conspecific male urine samples between control and treatment groups in Experiment 1 (Exp1) (a) ( $n=15$ for test female rats of each species), and Experiment 2 (Exp2) (b) ( $n=18$ for test females of each species). Paired $t$-test or Wilcoxon signed-rank test; ${ }^{*} p<0.05,{ }^{* *} p<0.01$

humiliatus exerts completely opposite effects on their male scent signals, which were enhanced in $R$. tanezumi, but inhibited in $R$. $n$. humiliatus. The results from Experiments 1 and 2 were not identical; however, they were generally consistent with one another. As sexual attractiveness is often correlated with reproductive success and fitness in male animals, the reproductive success of $R . n$. humiliatus may be suppressed due to reduced sexual attractiveness, and augmented in $R$. tanezumi due to increased sexual attractiveness resulting from chronic interspecific competition. Such asymmetric competition effects on scent signals and reproductive behavior may have facilitated the invasive $R$. tanezumi population to replace that of the native $R$. n. humiliatus [41, 43, 62-65]. Our results, therefore, warrant further investigation in the laboratory and the field $[46,66]$. Although rodents can emit species-specific ultrasonic vocalizations that are behaviorally important for mating, nursing, aggression, defense, and emotion within species, the effects of ultrasound-mediated chronic competition between closely related species appear to be very weak [67-69]. Therefore, we believe that nonphysical chronic interspecific interactions between $R$. tanezumi and $R$. $n$. humiliatus are likely to have been primarily mediated by chemical signals in our experiments.

In addition, chronic stress often impairs the sexual attractiveness of urine odor and decreases the levels of volatile pheromones in male mouse urine [47-49]. For example, both the presence of a predator and its scent can inhibit the sexual attractiveness of male mouse urine

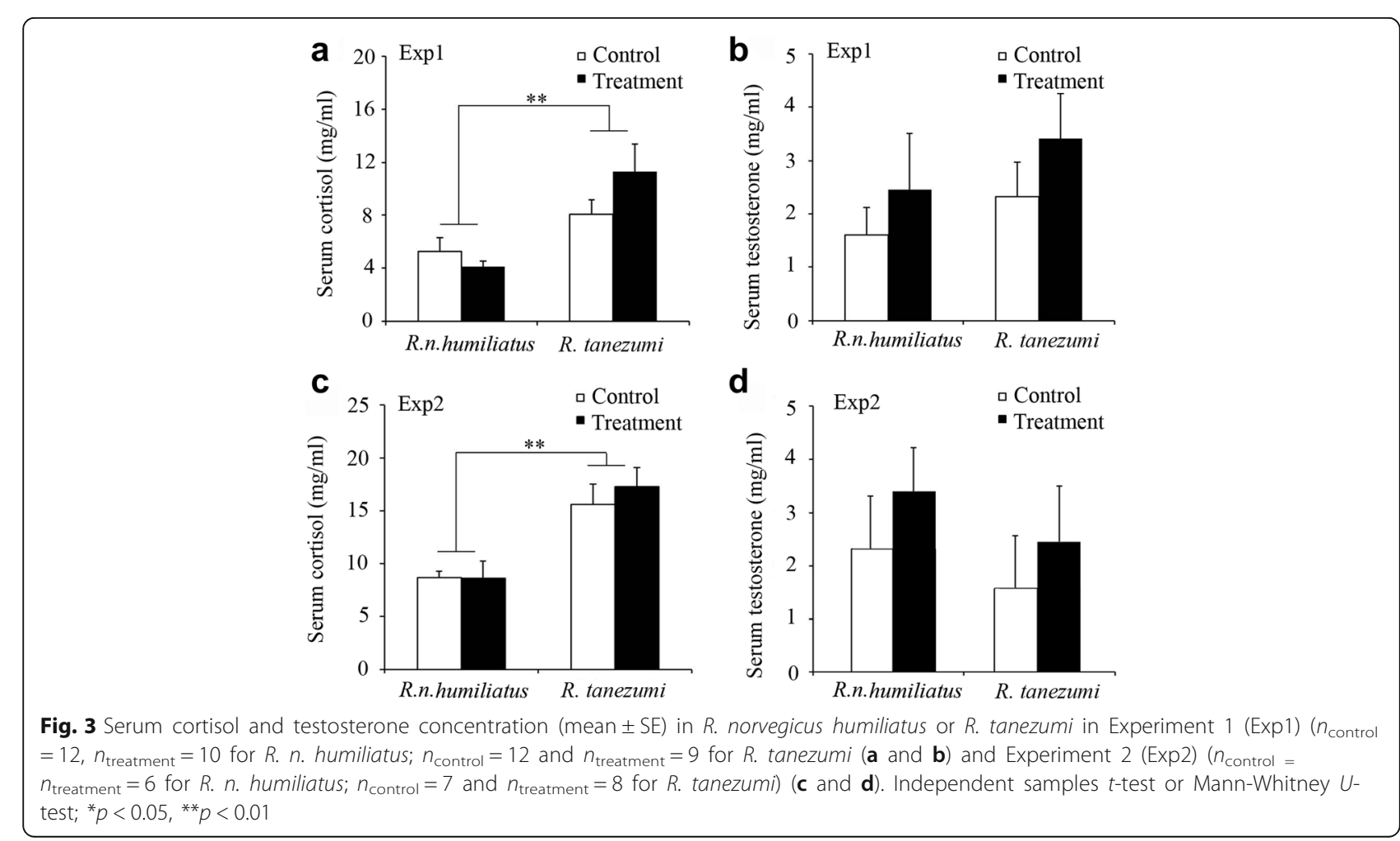



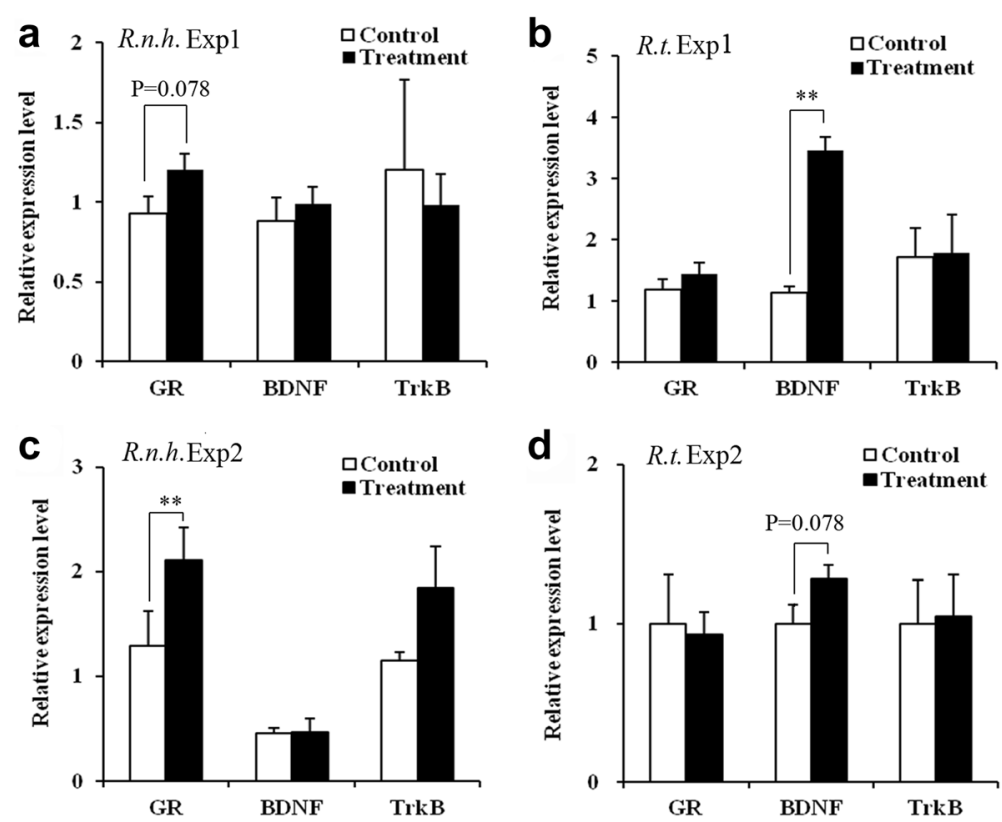

Fig. 4 Comparison of hippocampal expression of GR, BDNF, and TrkB mRNA (mean \pm SE) between control and treatment groups of $R$. norvegicus humiliatus (R.n.h.) (a and c) or R. tanezumi (R.t.) (b and $\mathbf{d}$ ) in Experiment 1 (Exp1) $\left(n_{\text {control }}=n_{\text {treatment }}=8\right.$ for $R$.n.h. and $n_{\text {control }}=$ $n_{\text {treatment }}=8$ for R.t.) and Experiment 2 (Exp2) $\left(n_{\text {control }}=n_{\text {treatment }}=6\right.$ for R.n.h.; $n_{\text {control }}=7$ and $n_{\text {treatment }}=8$ for R.t.). Independent samples t-test or Mann-Whitney $U$-test; ${ }^{*} p<0.05,{ }^{* *} p<0.01$

[48]. However, low predation risk, reflected as a low dose of predator scent, has a positive effect, boosting the sexual attractiveness of male mouse urine [36, 47, 70]. In intraspecific male-male competition, two opponents can form a stable dominance-submission relationship, in which the dominant partner has more volatile pheromones in the urine and greater sexual attractiveness compared with the submissive partner [49, 71]. Here, particularly in Experiment 2, the sexual attractiveness of male urine was augmented in $R$. tanezumi, but suppressed in $R . n$. humiliatus, as a result of exposure to heterospecific stimuli, indicating that $R$. n. humiliatus may be stressed by $R$. tanezumi. Coincidentally, juvenile $R$. n. humiliatus rats exposed to $R$. tanezumi odor gained more body weight than those exposed to their own species in Experiment 2, possibly reflecting the influence of a stressor $[44,72]$.

The influence of nonphysical competition-induced stress was further confirmed by the observation of upregulated hippocampal GR mRNA levels in $R$. n. humiliatus in response to $R$. n. humiliatus cues. As reported in previous studies of competition stress, we detected alterations in the expression of GR and BDNF mRNA in the hippocampus, but no differences in blood cortisol and testosterone levels in $R$. n. humiliatus experiencing chronic stress due to the presence of $R$. tanezumi $[20,55,56]$. GRs are key mediators of the neuroendocrine response to stress, and stressorspecific alterations in $G R$ mRNA levels are more pronounced in male than in female rodents [73]. Hippocampal $G R$ has been implicated in negative feedback inhibition of the HPA axis and can mediate the deleterious effects of blood glucocorticoids on hippocampal neuron survival and function $[52,59]$. The expression of hippocampal $G R$ can be affected by stressful stimuli and is adaptively downregulated to protect the hippocampus from glucocorticoid hypersecretion in acute stress and in the early stages of chronic stress $[52,59]$. In the late stages of chronic stress, blood glucocorticoid may return to control levels and hippocampal $G R$ expression may be upregulated due to the buffering effect of repeated stress and habituation effects [74]. Therefore, the upregulation of hippocampal GR mRNA observed in $R$. $n$. humiliatus in our study may indicate that this species was physiologically impaired by long-term interaction with $R$. tanezumi.

In contrast, hippocampal BDNF mRNA levels were upregulated in $R$. tanezumi, particularly in Experiment 1 , after exposure to $R$. n. humiliatus. The neurotrophic factor, $B D N F$, is associated with neuronal development, survival, and plasticity, and has been found to decrease in response to acute and mild chronic stress, which may contribute to the neuronal atrophy/death observed in rodents suffering from chronic stress [57, 58]. Conversely, an enriched environment (EE) can ameliorate stress-induced symptoms, such as anxious behavior and increase hippocampal neurogenesis and BDNF protein 
levels in mice and rats [36, 70]. In this study, heterospecific cues from $R$. $n$. humiliatus enhanced hippocampal $B D N F$ gene expression in $R$. tanezumi, and an EE may therefore improve cognitive function, spatial memory, and local behavioral adaptation of invasive $R$. tanezumi. For example, it is conceivable that, if immature $R$. tanezumi rats of pioneer populations disperse into the range of $R$. n. humiliatus, the resulting heterospecific cues will promote the development and survival of $R$. tanezumi. Moreover, repeated encounters between adult rats of these two species during the invasion process may improve the neuroendocrine state and adaptive behavior of R. tanezumi.

\section{Conclusions}

The results of both experiments conducted in this study imply that chronic nonphysical interspecific stimuli, particularly scent signals, can have asymmetric effects on $R$. $n$. humiliatus and $R$. tanezumi, leading to detrimental effects on the sexual attractiveness and neuroendocrine system of the former, and favorable effects on the same factors in the latter. Thus, we infer that chronic interspecific interactions may contribute to the invasive success and northward expansion of $R$. tanezumi and the decline of native $R . n$. humiliatus populations in natural habitats. These results warrant further investigation in the field.

\section{Methods}

\section{Animals}

Wild $R$. tanezumi and $R$. n. humiliatus were captured from Shanxi Province and Beijing (China), respectively. Each rat species was maintained as an outbred colony of 300-400 rats in our laboratory. The rats used were of the third generations, weaned at 4 weeks of age, and caged in groups of same sex siblings prior to use. All animals were kept in plastic rat cages $(37 \times 26 \times$ $17 \mathrm{~cm})$, in two separate rooms (14:10 h light: dark photoperiod, lights on at 5:00 am) and were maintained at $25{ }^{\circ} \mathrm{C} \pm 2{ }^{\circ} \mathrm{C}$. Food (standard rat chow) and water were provided ad libitum.

\section{Experiment 1 (assessment of chemical signals and ultrasonic vocalization stimuli in adult animals)}

Twenty-two adult male rats of each rat species were randomly selected from the colonies at 14-18 weeks of age, and 10 paired with the other species and the others paired with their own species as a control. All pairs of rats were housed in the same cage for 2 months, and all cages were partitioned with perforated galvanized iron sheets containing one $0.3 \mathrm{~cm}$ diameter hole per $\mathrm{cm}^{2}$, to allow chemical and ultrasonic interactions (Fig. 5). Body weights were not significantly different between control and treatment groups of the same species (R. $n$. humiliatus: $169.4 \pm 9.069 \mathrm{~g}$ vs. $172.5 \pm 8.303 \mathrm{~g}, t=0.014$, $p=0.989 ; \quad R$. tanezumi: $135.4 \pm 7.248$ g vs. $127.2 \pm$ $4.397 \mathrm{~g}, t=1.281, p=0.218)$.

The sexual attractiveness of the odor of the urine from heterospecific or conspecific caged males was assessed using twelve estrous female rats of each species. All female subjects were between 14 and 18 weeks of age and had estrous cycles of 4-5 days, as determined by a vaginal smear examination. Females were used in experiments on the days that they came into estrus. Sixteen female rats of each species were used as urine recipients in Experiment 1.

\section{Experiment 2 (assessment of the effects of odor stimulus on young animals)}

Fifteen immature males (4 weeks old) of each species were individually caged and randomly assigned into two groups for 2 months. One group $(n=8)$ was kept in a room with the other species, while the other group $(n=7)$ remained in a room with its own species, as a control. Each rat room was $15 \mathrm{~m}^{2}$ and contained approximately 120 rats (Fig. 5). Body weights were not significantly different between the two groups of the same species ( $R$. n. humiliatus: $50.66 \pm 3.972 \mathrm{~g}$ vs. $49.31 \pm 4.533 \mathrm{~g}, t=0.225, p=0.826 ; R$. tanezumi: $47.36 \pm 6.177 \mathrm{~g}$ vs. $46.03 \pm 9.010 \mathrm{~g}, t=0.338, p$ $=0.740$ ). Eighteen female rats of each species in estrus were used as urine recipients in Experiment 2.

\section{Urine collection}

Within 3 days after the chronic interspecific interaction experiments, we individually collected rat urine using clean metabolic rat cages during the dark phase of the light cycle. Urine collection continued for $8 \mathrm{~h}$ daily. The urine from the metabolic cage was collected in a tube immersed in an ice box. Standard rat chow and water were freely available. Urine samples were stored at $-20{ }^{\circ} \mathrm{C}$ until use. Metabolic cages were washed thoroughly with water between urine collections.

\section{Behavioral tests of sexual attractiveness}

Olfactory preference tests were conducted in a twochoice box that consisted of a plastic rat cage that served as a start box and two Plexiglas choice tubes (internal diameter, $7.5 \mathrm{~cm}$; length, $50 \mathrm{~cm}$ ). The two choice tubes were symmetrically connected to the long side of the start box and each tube had a removable perforated galvanized iron sheet partition $5 \mathrm{~cm}$ away from the box to control rat access. An odorant presentation compartment partitioned by a perforated galvanized iron sheet from the other part of the tube was at the distal end of each $10 \mathrm{~cm}$ tube (Fig. 5).

Female rats were first test acclimated in the start box for $30 \mathrm{~min}$, then a microscope slide with a urine 

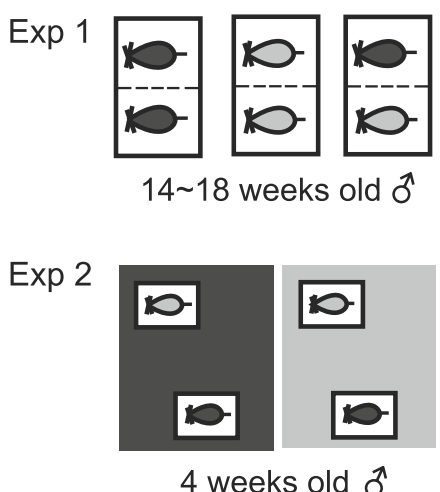

8 weeks

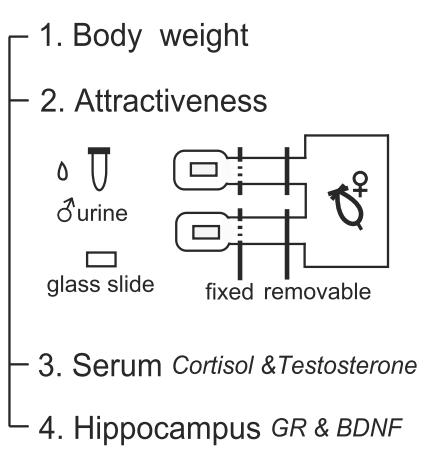

Fig. 5 Experimental set up. In Experiment 1, from 22 adult male rats of each rat species aged from 14 to 18 weeks, 10 were paired with the other species and the others were paired with their own species as a control. All pairs of rats were housed in the same cage for 2 months, and partitioned by perforated galvanized iron sheets. In Experiment 2, one group $(n=8)$ was kept in a room with the other species, and the other group $(n=7)$ remained in a room with its own species as a control. Each rat room was $15 \mathrm{~m}^{2}$ and contained approximately 120 rats of the same species. Eight weeks later, body weight, attractiveness of urine, serum cortisol and testosterone, and hippocampal GR and BDNF expression were measured. The attractiveness of male urine was determined using a two-choice box, consisting of a plastic (start box) and two Plexiglas choice tubes (internal diameter, $7.5 \mathrm{~cm}$; length, $50 \mathrm{~cm}$ ). The choice tubes were symmetrically connected to the start box and each tube had a removable perforated galvanized iron sheet partition $5 \mathrm{~cm}$ away from the box to control rat access. An odorant presentation compartment partitioned by a perforated galvanized iron sheet from the other part of the tube was at the distal end of each $10 \mathrm{~cm}$ tube. We painted the male urine on a glass slide, and then placed the slide in the presentation compartment

sample $(20 \mu \mathrm{L})$ was placed into the odorant presentation compartment of each tube. Female rats were simultaneously exposed to two urine samples from males conspecific to them, where one of the samples was from a male that had been housed with a conspecific male, and the other with a heterospecific male. We immediately opened the door to allow the females to freely respond to the urine. Between trials, the start box and choice tubes were cleaned thoroughly with water and $75 \%$ ethanol. All tests were recorded on video. Investigation times (i.e., the time each female spent in a choice tube) were determined from video replay using a Noldus ethovision XT system (Noldus, Wageningen, The Netherlands). We recorded the investigation time for $30 \mathrm{~min}$ in Experiment 1 and $1 \mathrm{~h}$ in Experiment 2 after the female initially entered either of the choice arms. If a test female did not enter either choice tube within $30 \mathrm{~min}$ (i.e., investigation time $=0$ ), we did not use the data.

\section{Blood and tissue sampling}

Two days after urine collection, all rats were decapitated (within $3 \mathrm{~min}$ ) and blood samples immediately collected. The hippocampus was immediately dissected, rapidly frozen in liquid nitrogen, and stored at $-80{ }^{\circ} \mathrm{C}$ until use. Blood samples were incubated at $4{ }^{\circ} \mathrm{C}$ in a refrigerator for $12 \mathrm{~h}$ and then centrifuged at $3000 \mathrm{rpm}$ for $15 \mathrm{~min}$ for serum collection. Serum samples were stored at $-80{ }^{\circ} \mathrm{C}$ until use. In Experiment 1, individual hippocampi from eight males were used for RNA isolation and quantitative real-time PCR; in Experiment 2, all of the hippocampi were used.

\section{Cortisol and testosterone analysis}

Serum samples were analyzed in duplicate for cortisol using an Iodine $\left[{ }^{125} \mathrm{I}\right]$ cortisol RIA kit and for testosterone using an Iodine $\left[{ }^{125} \mathrm{I}\right]$ Testosterone RIA Kit (Beijing North Institute of Biological Technology, China). In detail, $100 \mu \mathrm{L}$ of iodine-125 labeled cortisol (or testosterone) was incubated with $50 \mu \mathrm{L}$ of serum at $37^{\circ} \mathrm{C}$ for $1 \mathrm{~h}$ in a water bath. Then, $500 \mu \mathrm{L}$ of immune separating agent was added to each sample tube and samples incubated at room temperature for $15 \mathrm{~min}$. Sample tubes were then centrifuged at $3800 \mathrm{rpm}$ for $15 \mathrm{~min}$ and the supernatant discarded. The remaining radioactivity bound to the tube was measured using a gamma scintillation counter calibrated for iodine- 125 using a radioimmunoassay system (XH6080, Xi'an Nuclear Instrument Factory, Xi'an, China). For both cortisol and testosterone, the intra-assay coefficients of variation were less than $10 \%$, and the inter-assay coefficients of variation were less than $15 \%$.

\section{Quantitative real-time PCR}

Isolation of total hippocampal RNA was performed using Trizol reagent (Invitrogen, Life Technologies, Grand Island, NY, USA) according to the manufacturer's instructions. Total RNA concentration was determined using a NanoDrop spectrophotometer (Thermo Fisher Scientific Inc., Waltham, USA). Reverse-transcription 
Table 1 Primer sequences for real-time PCR

\begin{tabular}{lll}
\hline Gene & Forward Primer 5' 5 $^{\prime \prime}$ & Reverse Primer 5'-3' \\
\hline GAPDH & GACAATGAATATGGCTAC & TTATTGATGGTATTCGAGA \\
& AGCAAC & GAAGG \\
GR & AGGCAGTGTGAAATGTA & GAGGCTTACAATCCTCATTC \\
& TCCCAC & GTGT \\
BDNF & GAAGGGCCAGGTCGATT & GACGGAAACAGAACGAAC \\
& AGGTG & AGAA \\
TrkB & GAGACGAATCCAGCCC & CACAGACTTCCCTTCCTCCA \\
& CGACAC & CCG \\
\hline
\end{tabular}

was performed using a PrimeScript ${ }^{\oplus} \mathrm{RT}$ reagent Kit With gDNA Eraser (Perfect Real Time) (Takara Bio Inc., Dalian, China), following the manufacturer's protocol. The resulting cDNA was amplified using an Mx3005P quantitative PCR system (Stratagene, La Jolla, CA, USA) and the relative abundance of the mRNA of the target genes determined using a SYBR Green RealMasterMix Kit (Tiangen, Beijing, China) according to the manufacturer's instructions. PCR primers were designed using NCBI Primer Blast (http://www.ncbi.nlm.nih.gov/tools/ primer-blast) and the sequences are listed in Table 1. The housekeeping gene, GAPDH, was used as a control to normalize the relative mRNA levels. Data were analyzed as previously described [35].

\section{Statistical analyses}

The distributions of raw data were examined using Kolmogorov-Smirnov tests. If data were normally distributed, $t$-tests for paired-samples were used for the behavioral data and independent $t$-tests were used for the body weight, serum hormone and mRNA expression data. If the data were not normally distributed, Wilcoxon signed-rank and Mann-Whitney $U$ tests were used. All statistical analyses were conducted using the SPSS software package (v15.0, SPSS Inc., Chicago, IL, USA). Alpha was set at $P \leq 0.05$.

\section{Acknowledgements}

Not applicable

\section{Funding}

This work was supported by grants from the National Natural Science Foundation of China (31572277), the Strategic Priority Research Program of the Chinese Academy of Sciences (No. XDB1 1010400), and the State Key Laboratory of Integrated Management of Pest Insects and Rodents (ChineselPM1514).

\section{Availability of data and materials}

Not applicable

\section{Authors' contributions}

$J X Z$ and $Z Y H$ conceived and designed the experiments. HLG, ZYH, $H J T$, and $J H Z$ performed the experiments $Y H Z, H L G$, and JXZ wrote and revised the manuscript. All authors read and approved the final manuscript.

\section{Competing interests}

The authors declare that they have no competing interests.

\section{Consent for publication}

Not applicable

\section{Ethics approval and consent to participate}

Animal maintenance and handling complied with the Institutional Guidelines for Animal Use and Care at the Institute of Zoology, Chinese Academy of Sciences. Ethics approval was obtained from the Institutional Ethics Committee of the Institute of Zoology, Chinese Academy of Sciences (approval number IOZ12017).

\section{Publisher's Note}

Springer Nature remains neutral with regard to jurisdictional claims in published maps and institutional affiliations.

\section{Author details}

${ }^{1}$ State Key Laboratory of Integrated Management of Pest Insects and Rodents in Agriculture, Institute of Zoology, Chinese Academy of Sciences, No.1-5 Beichen West Road, Chaoyang District, Beijing 100101, China. ${ }^{2}$ College of Life Sciences, University of Chinese Academy of Sciences, Beijing 100049, China.

Received: 8 August 2016 Accepted: 2 March 2017

Published online: 12 April 2017

\section{References}

1. Musser GG, Carleton MD. Superfamily Muroidea. In: Wilson DE, Reeder DM, editors. Mammal species of the world a taxonomic and geographic reference. Baltimore: Johns Hopkins University Press; 2005. p. 894-1531.

2. Robins JH, McLenachan PA, Phillips MJ, Craig L, Ross HA, Matisoo-Smith E. Dating of divergences within the Rattus genus phylogeny using whole mitochondrial genomes. Mol Phylogen Evol. 2008;49:460-6.

3. Deinum EE, Halligan DL, Ness RW, Zhang Y-H, Cong L, Zhang J-X, Keightley PD. Recent evolution in rattus norvegicus is shaped by declining effective population size. Mol Biol Evol. 2015;32:2547-58.

4. Wu DL. Subspecies of the brown rat (Rattus norvegicus Berkenhout) in China. Acta Theriol Sin. 1982;2:107-12.

5. Zhu LB, Qian GZ. The relation between energetic regulation of two rats and their geographical distribution. Acta Theriol Sin. 1985;5:182.

6. Koh HS. Systematic studies on Korean rodents: VI. Analyses of morphometric characters, chromosomal karyotypes and mitochondrial DNA in two species of genus Rattus. Korean J Syst Zool. 1992;8:231-42.

7. Zhang MW, Guo C, Wang Y, Hu ZJ, Chen AG. A review of the studies on the Asian house rat (Rattus tanezumi) in China. Zool Res. 2000;21:487-97.

8. Zou B, Wang TL, Ning ZD, Liu S. The population of the Asian house rat (Rattus tanezumi) has been established in the Linfen District of Shanxi Province. Plant Prot. 1992:18:51.

9. Hou XF, Jiang XC. A survey of the Asian house rat (Rattus tanezumi) in Shijiazhuang District, Hebei Province from 2004 to 2007. Chin J Vector Biol Control. 2008;19:125

10. Guo S. Population genetics of the Asian house rat in some areas of China. MSc thesis. Beijing: Chinese Center for Disease Control and Prevention; 2012.

11. Lack JB, Hamilton MJ, Braun JK, Mares MA, Van den Bussche RA. Comparative phylogeography of invasive Rattus rattus and Rattus norvegicus in the US reveals distinct colonization histories and dispersal. Biol Invasions. 2013;15:1067-87.

12. Bennett AE, Thomsen M, Strauss SY. Multiple mechanisms enable invasive species to suppress native species. Am J Bot. 2011;98:1086-94.

13. Huang HW, Zou ZT, Tian ZZ, Hu XY, Zhao Y. Test of resistance of rattus tanezumi to warfarin in Xingyi City, Guizhou Province, China. Chin J Vec Biol Contr. 2012;23:554-5.

14. Nielsen BL, Rampin O, Meunier N, Bombail V. Behavioral responses to odors from other species: introducing a complementary model of allelochemics involving vertebrates. Front Neurosci. 2015;9:226.

15. Teng HJ, Zhang YH, Shi CM, Zhang JX. Whole-genome sequencing reveals genetic variations of the Asian house rat. G3-Genes Genom Genet. 2016;6: 1969-77.

16. Amarasekare P. Interference competition and species coexistence. Proc R Soc B. 2002;269:2541-50.

17. Yom-Tov Y, Yom-Tov S, Moller H. Competition, coexistence, and adaptation amongst rodent invaders to Pacific and New Zealand islands. J Biogeogr. 1999;26:947-58. 
18. Stuart YE, Campbell TS, Hohenlohe PA, Reynolds RG, Revell LJ, Losos JB. Rapid evolution of a native species following invasion by a congener. Science. 2014;346:463-6.

19. Simeonovska-Nikolova DM. Interspecific social interactions and behavioral responses of Apodemus agrarius and Apodemus flavicollis to conspecific and heterospecific odors. J Ethol. 2007;25:41-8.

20. Liesenjohann M, Liesenjohann T, Palme R, Eccard JA. Differential behavioural and endocrine responses of common voles (Microtus arvalis) to nest predators and resource competitors. BMC Ecol. 2013;13:33.

21. Schoener TW. Field experiments on interspecific competition. Am Nat. 1983; 122:240-85.

22. Harris MR, Siefferman L. Interspecific competition influences fitness benefits of assortative mating for territorial aggression in eastern bluebirds (sialia sialis). PLoS One. 2014;9:e88668.

23. Foster SP. Interspecific competitive interactions between Rattus norvegicus and $R$. rattus. MSC thesis. Hamilton: University of Waikato; 2010.

24. Vivanco JM, Bais HP, Stermitz FR, Thelen GC, Callaway RM. Biogeographical variation in community response to root allelochemistry: novel weapons and exotic invasion. Ecol Lett. 2004;7:285-92.

25. Apfelbach R, Blanchard CD, Blanchard RJ, Hayes RA, McGregor IS. The effects of predator odors in mammalian prey species: A review of field and laboratory studies. Neurosci Biobehav Rev. 2005;29:1123-44.

26. Sbarbati A, Osculati F. Allelochemical communication in vertebrates: kairomones, allomones and synomones. Cells Tissues Organs. 2006;183:206-19.

27. Hurst $J$ L. The functions of urine marking in a free-living population of house mice, Mus-domesticus rutty. Anim Behav. 1987;35:1433-42.

28. Hurst $\mathrm{J}$. Female recognition and assessment of males through scent. Behav Brain Res. 2009:200:295-303.

29. Brennan PA, Zufall F. Pheromonal communication in vertebrates. Nature. 2006:444:308-15.

30. Johansson BG, Jones TM. The role of chemical communication in mate choice. Biol Rev. 2007:82:265-89.

31. Smadja C, Ganem G. Subspecies recognition in the house mouse: a study of two populations from the border of a hybrid zone. Behav Ecol. 2002;13:312-20.

32. Robertson DHL, Hurst JL, Searle JB, Gunduz I, Beynon RJ. Characterization and comparison of major urinary proteins from the house mouse, Mus musculus domesticus, and the aboriginal mouse, Mus macedonicus. J Chem Ecol. 2007:33:613-30

33. Stopkova R, Stopka P, Janotova K, Jedelsky PL. Species-specific expression of major urinary proteins in the house mice (Mus musculus musculus and Mus musculus domesticus). J Chem Ecol. 2007;33:861-9.

34. Soini HA, Wiesler D, Koyama S, Feron C, Baudoin C, Novotny MV. Comparison of urinary scents of two related mouse species, Mus spicilegus and Mus domesticus. J Chem Ecol. 2009:35:580-9.

35. Mucignat-Caretta C, Redaelli M, Orsetti A, Perriat-Sanguinet M, Zagotto G, Ganem G. Urinary volatile molecules vary in males of the 2 European subspecies of the house mouse and their hybrids. Chem Senses. 2010;35: 647-54

36. Zhang YH, Zhang JX. Urine-derived key volatiles may signal genetic relatedness in male rats. Chem Senses. 2011;36:125-35.

37. Zhang $\mathrm{YH}$, Zhang JX. A male pheromone-mediated trade-off between female preferences for genetic compatibility and sexual attractiveness in rats. Front Zool. 2014;11:73.

38. Zhang YH, Du YF, Zhang JX. Uropygial gland volatiles facilitate species recognition between two sympatric sibling bird species. Behav Ecol. 2013; 24:1271-8.

39. Roberts SC, Gosling LM. Genetic similarity and quality interact in mate choice decisions by female mice. Nat Genet. 2003;35:103-6.

40. Roberts SA, Simpson DM, Armstrong SD, Davidson AJ, Robertson DH, McLean L, Beynon RJ, Hurst JL. Darcin: a male pheromone that stimulates female memory and sexual attraction to an individual male's odour. BMC Biol. 2010;8:75

41. Kumar V, Vasudevan A, Soh LJT, Le Min C, Vyas A, Zewail-Foote M, Guarrac FA. Sexual attractiveness in male rats is associated with greater concentration of major urinary proteins. Biol Reprod. 2014:91:150.

42. Dijkstra PD, Verzijden MN, Groothuis TGG, Hofmann HA. Divergent hormonal responses to social competition in closely related species of haplochromine cichlid fish. Horm Behav. 2012;61:518-26.

43. Zhang $Y H$, Liang HC, Guo HL, Zhang JX. Exaggerated male pheromones in rats may increase predation cost. Curr Zool. 2015;62:431-37.
44. Zhang JX, Rao XP, Sun LX, Wang DW, Liu DZ, Zhao CH. Cohabitation impaired physiology, fitness and sex-related chemosignals in golden hamsters. Physiol Behav. 2008;93:1071-7.

45. Andersson M, Simmons LW. Sexual selection and mate choice. Trends Ecol Evol. 2006;21:296-302

46. Drickamer LC, Gowaty PA, Holmes CM. Free female mate choice in house mice affects reproductive success and offspring viability and performance. Anim Behav. 2000;59:371-8.

47. Zhang JX, Sun LX, Bruce KE, Novotny MV. Chronic exposure of cat odor enhances aggression, urinary attractiveness and sex pheromones of mice. J Ethol. 2008;26:279-86.

48. Huo Y, Fang Q, Shi YL, Zhang YH, Zhang JX. Chronic exposure to a predator or its scent does not inhibit male-male competition in male mice lacking brain serotonin. Front Behav Neurosci. 2014;8:116.

49. Fang $Q$, Zhang $Y H$, Shi $Y L$, Zhang JH, Zhang JX. Individuality and transgenerational inheritance of social dominance and sex pheromones in isogenic male mice. J Exp Zool Part B. 2016;326:225-36.

50. Liu YJ, Zhang YH, Li LF, Du RQ, Zhang JH, Zhang JX. Cross-fostering of male mice subtly affects female olfactory preferences. PLoS One. 2016;11: e0146662.

51. Stankiewicz AM, Goscik J, Majewska A, Swiergiel AH, Juszczak GR. The effect of acute and chronic social stress on the hippocampal transcriptome in mice. PLoS One. 2015;10:e0142195.

52. Herman JP, Spencer R. Regulation of hippocampal glucocorticoid receptor gene transcription and protein expression in vivo. J Neurosci. 1998;18:7462-73

53. Nibuya M, Takahashi M, Russell DS, Duman RS. Repeated stress increases catalytic TrkB mRNA in rat hippocampus. Neurosci Lett. 1999;267:81-4

54. Wosiski-Kuhn M, Erion JR, Gomez-Sanchez EP, Gomez-Sanchez CE, Stranahan AM. Glucocorticoid receptor activation impairs hippocampal plasticity by suppressing BDNF expression in obese mice. Psychoneuroendocrinology. 2014;42:165-77.

55. Kirby ED, Muroy SE, Sun WG, Covarrubias D, Leong MJ, Barchas LA, Kaufer D. Acute stress enhances adult rat hippocampal neurogenesis and activation of newborn neurons via secreted astrocytic FGF2. Flife. 2013:2:e00362.

56. Saaltink DJ, Vreugdenhil E. Stress, glucocorticoid receptors, and adult neurogenesis: a balance between excitation and inhibition? Cell Mol Life Sci. 2014;71:2499-515.

57. Pizarro JM, Lumley LA, Medina W, Robison CL, Chang WLE, Alagappan A, Bah MJ, Dawood MY, Shah JD, Mark B, et al. Acute social defeat reduces neurotrophin expression in brain cortical and subcortical areas in mice. Brain Res. 2004:1025:10-20.

58. Murakami S, Imbe H, Morikawa Y, Kubo C, Senba E. Chronic stress, as well as acute stress, reduces BDNF mRNA expression in the rat hippocampus but less robustly. Neurosci Res. 2005:53:129-39.

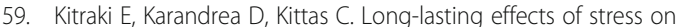
glucocorticoid receptor gene expression in the rat brain Neuroendocrinology. 1999;69:331-8.

60. Chen LJ, Shen BQ, Liu DD, Li ST. The effects of early-life predator stress on anxiety- and depression-like behaviors of adult rats. Neural Plas. 2014;2014: 163908.

61. Sanchez MM, Ladd CO, Plotsky PM. Early adverse experience as a developmental risk factor for later psychopathology: Evidence from rodent and primate models. Dev Psychopathol. 2001;13:419-49.

62. Wedell N, Tregenza T. Successful fathers sire successful sons. Evolution. 1999:53:620-5.

63. Kortet $\mathrm{R}$, Hedrick $A$. The scent of dominance: female field crickets use odour to predict the outcome of male competition. Behav Ecol Sociobiol. 2005:59:77-83.

64. Taylor ML, Wedell N, Hosken DJ. The heritability of attractiveness. Curr Biol. 2007;17:R959-60.

65. Hosken DJ, Taylor ML, Hoyle K, Higgins S, Wedell N. Attractive males have greater success in sperm competition. Curr Biol. 2008;18:R553-4.

66. Guillaumet A, Leotard G. Annoying neighbors: multi-scale distribution determinants of two sympatric sibling species of birds. Curr Zool. 2015;61:10-22

67. Kapusta J, Sales GD. Male-female interactions and ultrasonic vocalization in three sympatric species of voles during conspecific and heterospecific encounters. Behaviour. 2009:146:939-62.

68. Wohr M, Schwarting RKW. Affective communication in rodents: ultrasonic vocalizations as a tool for research on emotion and motivation. Cell Tissue Res. 2013:354:81-97. 
69. Musolf K, Meindl S, Larsen AL, Kalcounis-Rueppell MC, Penn DJ. Ultrasonic vocalizations of male mice differ among species and females show assortative preferences for male calls. PLoS One. 2015;10:e0134123.

70. Cao WY, Duan J, Wang XQ, Zhong XL, Hu ZL, Huang FL, Wang HT, Zhang J, $L i F$, Zhang JY, et al. Early enriched environment induces an increased conversion of proBDNF to BDNF in the adult rat's hippocampus. Behav Brain Res. 2014;265:76-83.

71. Guo H, Fang Q, Huo Y, Zhang Y, Zhang J. Social dominance-related major urinary proteins and the regulatory mechanism in mice. Integr Zool. 2015; 10:543-54.

72. Afolabi AO, Alagbonsi IA, Oke OD. Early prenatal stress increases body weight and reduces nociception in adult male rats. Annu Res Rev Biol. 2014; 4:1431-8.

73. Karandrea D, Kittas C, Kitraki E. Forced swimming differentially affects male and female brain corticosteroid receptors. Neuroendocrinology. 2002;75: 217-26.

74. Gadek-Michalska A, Spyrka J, Rachwalska P, Tadeusz J, Bugajski J. Influence of chronic stress on brain corticosteroid receptors and HPA axis activity. Pharmacol Rep. 2013;65:1163-75.

Submit your next manuscript to BioMed Central and we will help you at every step:

- We accept pre-submission inquiries

- Our selector tool helps you to find the most relevant journal

- We provide round the clock customer support

- Convenient online submission

- Thorough peer review

- Inclusion in PubMed and all major indexing services

- Maximum visibility for your research

Submit your manuscript at www.biomedcentral.com/submit
Biomed Central 